\title{
MuSER (Multiple Sclerosis Expected Rate) Predictive Model Development
}

\author{
Davide Frumento* \\ Department of Experimental Medicine, University of Genoa, Italy
}

*Corresponding author: Davide Frumento, Section of Biochemistry, Department of Experimental Medicine, University of Genoa, Genova (GE), Italy.

To Cite This Article: Davide Frumento. MUSER (Multiple Sclerosis Expected Rate) Predictive Model Development. Am J Biomed Sci \& Res. 2019 - 2(2). AJBSR.MS.ID.000578. DOI: 10.34297/AJBSR.2019.02.000578

Received: March 28, 2019 | Published: April 04, 2019

\begin{abstract}
Multiple Sclerosis (MS) is the most diffused among rare neurological pathologies, as it affects about $0.031 \%$ people all over the world. Its prevalence in the United States (US) was calculated to be around 0.14\%, but according to National Multiple Sclerosis Society (NMSS) MS is not properly monitored and registered within American territory and the creation of a MS archive is expected to ameliorate the calculus accuracy. The aim of this work is to develop a simple but reliable biostatistical predictive model called MuSER (Multiple Sclerosis Expected Rate); it was projected based on the ascending trend that was observed during previous studies, although not dependable, is theoretically reliable, at least considering R2 coefficients. Efficiency of MuSER model will be assessed at the end of 2019.
\end{abstract}

In order to predict MS incidence within an ethnically homogeneous population. Although not absolutely dependable, is theoretically reliable, at least considering R2 coefficients. Efficiency of MuSER model will be assessed at the end of 2019.

\section{Introduction}

Multiple Sclerosis (MS) is the most diffused among rare neurological pathologies, as it affects about $0.031 \%$ people all over the world [1]. Its prevalence in the United States (US) was calculated to be around $0.14 \%$ [2], but according to National Multiple Sclerosis Society (NMSS) MS is not properly monitored and registered within American territory and the creation of a MS archive is expected to ameliorate the calculus accuracy. Conversely, it is reasonable to infer that a more precise cases registration could increase both incidence and prevalence rates. In fact, about 10000 new cases per year are reported to be diagnosed in US; interestingly, this incidence trend has constantly grown since the 50s. This phenomenon has been partially ascribed to the evolution and sophistication of sensitive diagnostic techniques [3].

Albeit MS onset is not age-dependent, starting symptoms are most commonly observable during early adulthood, generally between 20 and 50 years of age. Accordingly, within US, about $50 \%$ of diagnoses are registered before the age of 30 [4]. MS is approximately $75 \%$ more diffused in women than men, and it has been demonstrated that such a ratio could increase over the next years [1,5]. Interestingly, MS shows no ethnic dependence, as it affects African-Americans, Asians, and Hispanics/Latinos, in addition to European-descending people [1]. Although MS was once expected to happen more frequently among Caucasians in
Western Europe and North America [6], a latter-day research demonstrated that the developing risk may be bigger in AfroAmerican women than in Caucasian ones [7]. With all that in mind, the aim of this work is to develop a simple but reliable biostatistical predictive model called MuSER (Multiple Sclerosis Expected Rate); it was projected based on the ascending trend that was observed during previous studies, in order to predict MS incidence within an ethnically homogeneous population.

Rationale behind MuSER (Multiple Sclerosis Expected Rate) model

This model was inspired by the previous paper [8], in which a novel approach was proposed. Such a system is based on a backward-wise methodological approach, in which the ethnogenetic background of patients should be mapped in order to have an accurate biostatistical scenario, going back to the isolated communities in which the disorder firstly arose. Then it will be possible to apply the system to the general population, considering the ethnic distribution. The first step was to develop the MuSER (Multiple Sclerosis Expected Rate) model, that was designed by considering the Italian Multiple Sclerosis (MS) incidence, registered during a 42-years long period. Since Italy, like other Europeans countries, is ethnically homogeneous [9], it was considered as an acceptable basis to start with. 


\section{Methods}

Italian MS annual incidence data relative, between 1965 and 2007 [10], were employed in order to build three Microsoft Excel dispersion graphs, differentiated by geographic area (Northern, Central and Southern Italy). After the insertion of tendency lines, the relative equations and $\mathrm{R} 2$ coefficients were calculated by the software. Then, since R2 theoretical accuracy coefficients were too low and non-reliable, outlier data were cancelled, both obtaining $\mathrm{R} 2$ factors higher than 0.90 and conserving a minimum $\mathrm{n}=5$.

\section{Results}

As it can be observed in Figure 1, the model is yet too inaccurate, having R2 values equals to $0.7369,0.5615$ and 0.5240 , respectively. By eliminating outliers Figure 2, R2 factors increased to 0.9190, 0.9651 and 0.9287 , respectively, reaching a theoretical accuracy higher than $90 \%$. According to the implemented model, mean expected Multiple Sclerosis incidence per 100000 people, for 2019, will be $10.78 \pm 2.24$ (Table 1).

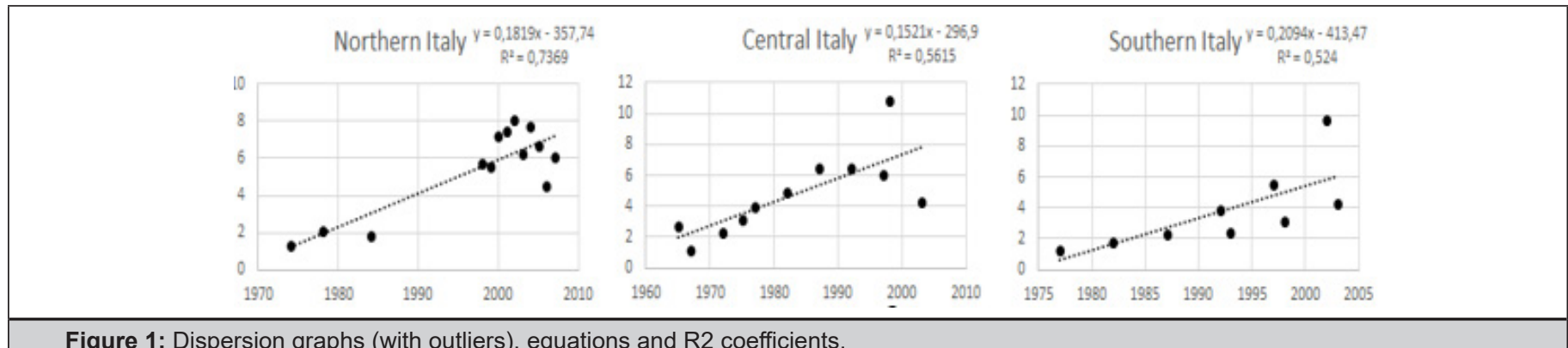

Figure 1: Dispersion graphs (with outliers), equations and R2 coefficients.

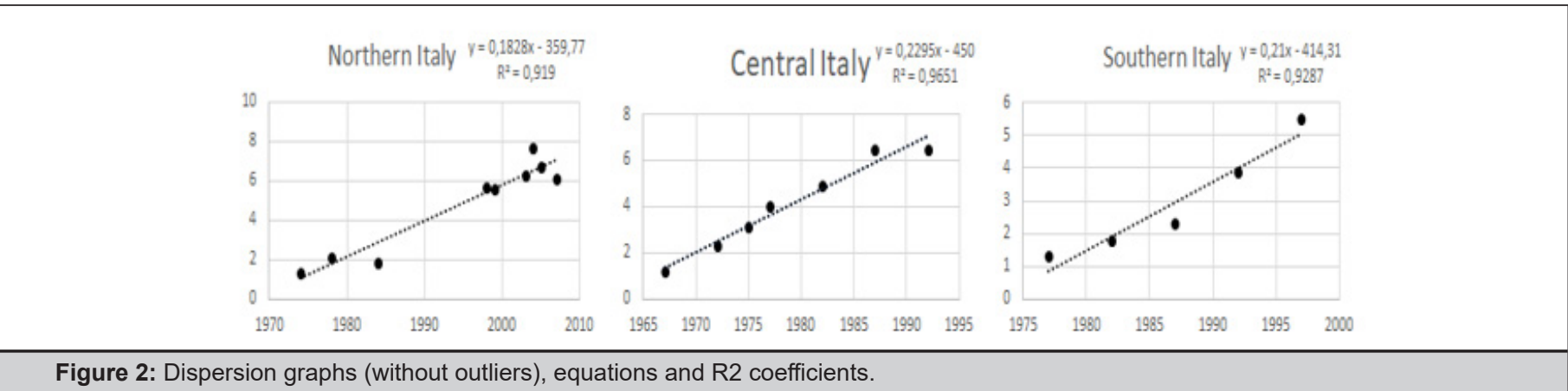

Table 1: Expected Multiple Sclerosis incidence on 100000 individuals, calculated for 2019.

\begin{tabular}{|l|l|l|l|l|l|l|}
\hline & \multicolumn{2}{|l|}{ With outliers } & & $\begin{array}{l}\text { Without out } \\
\text { outliers }\end{array}$ & \\
\hline \multirow{2}{*}{ Area } & $\begin{array}{l}\text { Incidence on } 100 \\
000\end{array}$ & & & $\begin{array}{l}\text { Incidence on } 100 \\
000\end{array}$ & & \\
\cline { 2 - 8 } & & Accuracy & SD & & Accuracy & SD \\
\hline Northern Italy & 9.52 & 73.69 & - & 9.3 & 91.9 & - \\
\hline Central Italy & 10.19 & 56.15 & - & 13.36 & 96.51 & - \\
\hline Southern Italy & 9.31 & 52.4 & - & 9.68 & 92.87 & - \\
\hline Whole country & 9.67 & 60.75 & 0.46 & 10.78 & 93.76 & 2.24 \\
\hline
\end{tabular}

\section{Conclusions}

It can be concluded MuSER (Multiple Sclerosis Expected Rate), although not dependable, is theoretically reliable, at least considering R2 coefficients. Efficiency of MuSER model will be assessed at the end of 2019.

\section{References}

1. National Multiple Sclerosis Society (2014) MS prevalence New York.

2. The Multiple Sclerosis Coalition (2014) The use of disease-modifying therapies in multiple sclerosis- Principles and current evidence: A consensus paper. The Multiple Sclerosis Coalition.

3. Kalb R (2012) Multiple sclerosis: The questions you have, the answers you need. Demos Medical Publishing, New York, USA.
4. Fraser RT, Kraft GH, Ehde DM, Johnson KL (2006) The MS work-book: Living fully with multiple sclerosis. New Harbinger Publications, Oakland.

5. Dunn SE, Steinman L (2013) The gender gap in multiple sclerosis: Intersection of science and society. JAMA Neurol 70(5): 634-635.

6. DeLuca J, Nocentini U (2011) Neurological, medical, and rehabilitative management in persons with multiple sclerosis. Neuro Rehabilitation 29(3): 197-219.

7. Langer-Gould A, Brara SM, Beaber BE, Zhang JL (2013) Incidence of multiple sclerosis in multiple racial and ethnic groups. Neurology 80(19): 1734-1739.

8. Frumento D (2019) Sarcoglycanopathies: a novel predictive approach. GSL J Public Health Epidemiol 2: 112. 
9. Lell TJ, Wallace DC (2000) The peopling of Europe from maternal and paternal perspectives. Am J Hum Genet 67 (6): 1376-1381.
10. Battaglia MA, Bezzini D (2017) Estimated prevalence of multiple sclerosis in Italy in 2015 Neurol Sci 38: 473-479. 